\title{
DISCIPLINAMIENTO DE LOS CUERPOS Y DE LAS PRÁCTICAS PEDAGÓGICAS EN EDUCACIÓN INFANTIL: RITOS E INTERDICCIONES DE LA ACCIÓN DOCENTE
}

Body and Pedagogic Practices Discipline in Childhood Education: Rites and Interdictions in Teachers' Action

Disciplinamento dos Corpos e das Práticas Pedagógicas na Educação Infantil: Ritos e Interditos da Ação Docente

\author{
Ana Cristina Richter (1) \\ Jaison José Bassani (2) \\ Alexandre Fernandez Vaz (3)
}

(1) Pós-doutoranda CNPq no Programa de Pós-Graduação em Educação da Universidade Federal de Santa Catarina; Doutora em Educação pela Universidade Federal do Paraná; Pesquisadora do Núcleo de Estudos e Pesquisas Educação e Sociedade Contemporânea (UFSC/CNPq). E-mail: ana_tinaa@uol.com.br

(2) Professor do Departamento de Educação Física e dos Programas de Pós-Graduação em Educação e Educação Física da Universidade Federal de Santa Catarina (UFSC); Vice-coordenador do Núcleo de Estudos e Pesquisas Educação e Sociedade Contemporânea (UFSC/CNPq).E-mail: jaisonbassani@uol.com.br

(3) Doutor pela Leibniz Universität Hannover, Alemanha; Professor do Programa de Pós-graduação em Educação e do Programa de Pós-graduação Interdisciplinar em Ciências Humanas, da Universidade Federal de Santa Catarina; Coordenadora do do Núcleo de Estudos e Pesquisas Educação e Sociedade Contemporânea (UFSC/CNPq); Pesquisador CNPq. E-mail alexfvaz@uol.com.br

\section{Resumen}

El trabajo considera escenas y voces de profesora de educación infantil actuantes en un jardín de la municipalidad de Florianópolis, Brasil. Los análisis, realizados bajo especialmente la tradición frankfurtiana, apuntan para una práctica pedagógica que en tiempos y espacios diversos intentan conservar la estabilidad, la seguridad y la unidad, así como la eficiencia de las acciones. Dicha constancia, que encuentra en el rito su modus operandi, establece padrones, comportamientos, acciones y comunicación pedagógica. $\mathrm{Su}$ legitimad se ubica en la producción del orden racional traducido en la eliminación de desvíos, en el abandono de la expresión mimética y en la renuncia del pensamiento, en favor de los hábitos y rutinas de la conservación de sí. 
Palabras-clave: Educación del cuerpo, Práctica Pedagógica, Educación Infantil, Tabues, Teoría Crítica.

\begin{abstract}
This paper aims to analyze teachers' speeches and takes of their practices in a public Kindergarten in Florianopolis, Brazil. Inspired in Frankfurt School concepts, interviews and observations were sources to be considered. The results point out that the practices look for tanking time and space over control, in sense of reaching stability, security and efficacy. Ritual is the modus operandi of those efforts: children and adults' bodies, senses and behaviors are dominated by prescribed techniques of pedagogic communications. A rational order appears in elimination of turnings, in banning of mimetic expression, in renunciation of thinking. Technique and systematic proceeding replace those faculties to reach habits and routines in sense of self conservation.
\end{abstract}

Keywords: Education of Body, Pedagogic Practice, Childhood Education, Taboos, Critical Theory.

\title{
Resumo
}

O trabalho focaliza cenas e vozes de professoras de educação infantil atuando em uma instituição pública de Florianópolis, Brasil. As análises, realizadas com o auxílio principalmente de conceitos da tradição frankfurtiana, apontam para uma prática pedagógica que percorre tempos e espaços que buscam conservar estabilidade, segurança e unidade, bem como a eficiência das ações. Essa constância, que encontra no rito o seu modus operandi, estabelece padrões, procedimentos e técnicas, que ordenam os corpos de crianças e adultos, sentidos, comportamentos, ações e comunicação pedagógica. Sua legitimidade reside na produção da ordem racional que se traduz em eliminação de desvios, abandono da expressão mimética e abdicação do pensamento em favor de hábitos e rotinas em prol da autoconservação.

Palavras chave: Educação do corpo, prática pedagógica, Educação Infantil, Tabus, Teoria Crítica. 


\section{Introdução}

Desde que a Educação Infantil foi integrada ao sistema educacional brasileiro, o Ministério da Educação tem elaborado e divulgado documentos no intuito de contribuir para o planejamento, desenvolvimento e avaliação de propostas educativas, bem como informar diretrizes, objetivos, metas e estratégias de ação voltadas para a primeira etapa da Educação Básica, visando melhorar a qualidade do atendimento nas instituições que atendem crianças entre 0 e 5 anos de idade (Brasil, 1998; 2005; 2006).

Os documentos têm apontado, entre outros aspectos, para a necessidade de superação do caráter assistencialista que demarca a história da Educação Infantil, frequentemente limitada a atender às necessidades básicas de higiene, alimentação e guarda das crianças, sob a orientação de profissionais sem formação ou precariamente preparados. A crítica aparece acompanhada da censura às rotinas, marcadas pela rigidez e por estratégias de disciplinamento, tais como a exigência de silêncio e o controle de movimentos, ritmos e posturas das crianças, que representariam um desrespeito aos direitos dos pequenos (Brasil, 2009a). Nesse contexto evidenciam-se as técnicas corporais e os cuidados com o corpo no interior desses ambientes educacionais, seja em termos de restrição das possibilidades de movimento, seja nas relações de severidade nas práticas comensais, nos momentos de repouso e de higiene e nos cuidados com a saúde das crianças.

Entretanto, a presença de um itinerário que envolva os cuidados, as brincadeiras e as situações de aprendizagem orientadas, é valorizada como guia para as ações das crianças, com fins de garantir, por meio de um espaço preparado e de aparatos disponíveis, a necessária segurança. A rotina é considerada essencial também aos professores, organizando o tempo e antevendo atividades diversas que incluam a ampla movimentação das crianças, maior e menor grau de concentração, bem como momentos de repouso, alimentação e higiene.

Para além do destaque ao planejamento do tempo de trabalho educativo realizado com as crianças, os documentos informam que a rotina institucional não deve prescindir de momentos de formação continuada que favoreçam o encontro entre os professores para que 
reflitam a respeito de suas práticas, realizem estudos e planejem as atividades cotidianas. Além disso, apontam para a necessidade de se oferecer ambientes separados dos espaços das crianças, com materiais e mobiliários adequados para que os adultos encontrem conforto e silêncio nos momentos de reunião, de estudo e planejamento, mas também nos de intervalo e descanso que compõem o cotidiano das instituições de atendimento à pequena infância.

Ocupamo-nos, neste texto, de concepções, práticas e vozes de professoras, considerando os distintos momentos que demarcam a rotina institucional, bem como demais períodos que dão forma ao dia-a-dia de trabalho dessas profissionais, tais como os momentos de intervalo e as paradas pedagógicas mensais, ocasiões em que as crianças são dispensadas da creche e equipe diretiva e docentes reúnem-se para estudar e debater temas relacionados à Educação Infantil, assistir palestras, organizar eventos coletivos etc. Partimos, para tal, de uma revisitação de dados de uma pesquisa ${ }^{1}$ de abordagem etnográfica desenvolvida em uma instituição pública municipal de atendimento à pequena infância, que objetivou traçar um inventário para estudos sobre a educação do corpo ${ }^{2} \mathrm{em}$ ambientes educacionais e que registrou a presença de uma pedagogia materializada a partir de uma rotina que tende a didatizar os gestos, conformar, disciplinar e ensinar a sujeitar-se, e que se coloca fortemente vinculada ao controle civilizador de uma dimensão vista como

\footnotetext{
${ }^{1}$ Trata-se de uma revisitação aos dados de pesquisa produzidos por ocasião da pesquisa de mestrado Sobre a Presença de uma Pedagogia do Corpo na Educação da Infância: retratos e vozes, lugares e tempos da corporalidade na rotina de uma creche (Richter, 2005), defendida junto ao Programa de Pós-Graduação em Educação da Universidade Federal de Santa Catarina (PPGE/UFSC/CNPq). O trabalho foi originalmente apresentado no VII Congresso Internacional de Teoria Crítica, Natureza, Sociedade: Crises, realizado na Universidade Federal de Campinas (UNICAMP), de 09 a 13 de setembro de 2010 (Disponível em http://www.unimep.br/anexo/adm/04062012162556.pdf). A presente versão apresenta pequenas, mas importantes modificações e avanços, inclusive no título. Agradecemos o apoio da CAPES (Coordenação de Aperfeiçoamento de Pessoal de Nível Superior) pela bolsa de mestrado, e do CNPq (Conselho Nacional de Desenvolvimento Científico e Tecnológico) pelo auxílio pesquisa e pela bolsa de produtividade em pesquisa (ambos no contexto do Programa de Pesquisas Teoria Crítica, Racionalidades e Educação - IV), que financiaram a realização do trabalho.

${ }^{2}$ Destaque-se que a educação do corpo não se limita à Educação Física, disciplina curricular presente também na educação de zero a cinco anos. "[A Educação Física] reúne apenas uma parte, seguramente importante, das técnicas corporais e dos cuidados com o corpo em ambientes educacionais. Essas técnicas e cuidados estão presentes em muitos outros momentos do cotidiano escolar, dos hábitos de higiene aos alimentares, dos imperativos disciplinares aos castigos, do espelho de classe aos preconceitos, dos ideais de beleza aos interditos de gênero." (Vaz, 2002:3).
} 
natureza desmedida, no interior da qual o corpo e a infância aparecem como outros da razão, ou, dito outra forma, como ameaças à racionalidade instrumental.

Na primeira parte tratamos da rotina institucional, apresentando cenas do cotidiano e recortes de entrevistas relacionadas ao dia-a-dia na creche. No capítulo seguinte focalizamos os intervalos das professoras, apontando para as suas ações e falas que aparecem ancoradas na ideia de um tempo livre. Na sequência, abordamos as paradas pedagógicas, enfatizando cenas que, embora sugiram uma interrupção do tempo, revelamse como pseudoatividade, uma vez desprovidas de reflexão. Nas considerações finais destacamos práticas pedagógicas presentes na instituição e sua relação com a busca por espaços e tempos que se distanciem de conflitos e tensões, procurando, assim, uma espécie de equilíbrio que encontra no rito seu modus operandi, buscando a segurança e a unidade no interior da instituição. Esse movimento aparece fortalecido por tabus que têm como base a compulsiva renúncia, o abandono como forma de mortificação que, em seu desenvolvimento ulterior, se converte em simulacro no cuidado excessivo ou na hostilidade dissimulada.

\section{Das configurações da rotina: o dia-a-dia na creche}

Os relatos dizem que cabe a cada professora da creche, entre outros aspectos, organizar os momentos planejando a distribuição dos mobiliários, introduzindo novos recursos e desenvolvendo atividades variadas, bem como oferecer cuidados adequados à saúde e à higiene e respeitar os interesses e necessidades das crianças na consecução do planejamento. Malgrado as nuances, os relatos apresentam uma síntese precisa da rotina de atividades que compõem o dia-a-dia, tal como se pode observar na passagem retratada por uma profissional da equipe pedagógica, abaixo transcrita:

Elas [as professoras] chegam às oito horas. As auxiliares já chegaram às sete. Já receberam as crianças, já falaram com as famílias, já passaram os recados. [...] A sala já está estruturada, as crianças já estão brincando. Elas chegam, organizam as crianças, fazem o lanche. Voltam para a sala. Aí, dependendo do planejamento de cada um, vão fazer uma atividade dirigida ou vão continuar o que estavam fazendo anteriormente, continuar brincando. Tem uma rotina que elas vão pro parque, as crianças correm, têm espaço livre. [...] Depois elas levam para lavar as mãos, fazer a higiene. [...] Daí o almoço no refeitório e uma vez na sala. [...] Aí depois as 
crianças vão dormir, as professoras auxiliares fazem as crianças descansarem. [...] Então elas têm intervalo. À tarde repete tudo da manhã [fala rindo], e o horário de saída, menos o sono. Aí tem o horário de saída. É o encontro com os pais ou irmãos quando é relatado alguma coisa que acontece. Como a criança tava naquele dia. E depende da família também, porque tem família que chega, só pega, sai e nenhuma pergunta. Às vezes a gente tem que gritar, chamar "ô mãe, vem cá", que quer colocar que a criança não tava bem de saúde. É outro problema também, o das doenças.

Segundo o depoimento de uma professora que atua com crianças menores de um ano, não seria possível, no que se refere aos momentos de higiene, alimentação e sono, afastar-se "daquele tal de assistencialismo", mostrando como foi incorporada, no plano discursivo, a crítica aos modelos entranhados na história da educação da infância. Diz-nos ela:

Chego à creche. A gente começa a dar lanche. O primeiro lanche da manhã. Em seguida a gente começa a ver as fraldas de todos. Se tiver cocô a gente troca. Se tiver só xixi a gente não troca. Só vai trocar mais tarde. E como a gente já conhece bem, a gente já sabe: aquele ali não faz cocô agora. Vamos deixar para trocar depois. Então começa a trocar. Troca todos, dá banho em alguns. Depois a gente faz alguma atividade com eles, leva no solário... sempre eles vão para a rua de manhã. Agora que o sol já está muito quente aí a gente bota para dentro antes. Quando está muito frio também não dá para deixar na rua. [...] Geralmente a gente está dando banho em todos porque está muito calor. Eles dormem mais tranqüilos com banho. [...] Lá pela uma e vinte a gente começa a dar o lanche da tarde. [...] Depois a gente vai olhar todos. Saber se precisa trocar de novo. [...] Tem que economizar fralda porque algumas mães mandam pouca fralda. Aí a gente começa a trocar.

Na opinião da mãe de uma criança, para sua "sorte" ela está muito satisfeita com a creche, pois “a professora é boa e não judia ${ }^{3}$ das crianças". Foi neste ambiente educacional que seus filhos aprenderam "a ser disciplinados", assim como "a hora de saber brincar, a hora de guardar os brinquedos. Se é hora de brincar, é hora de brincar [...]. Se é hora de fazer atividade não tem que ir pro parque na hora da atividade, porque aquela hora é da atividade e não do parque. Eles [as crianças] passam um pouquinho pra gente, né?”

\footnotetext{
${ }^{3}$ Não há como não destacar a presença clandestina de um vocabulário eivado de preconceitos na creche e na comunidade que a compõe. Neste caso, materializa-se com uma expressão antissemita.
} 
Nos documentos vigora o respeito àqueles que seriam os direitos fundamentais dos pequenos: à brincadeira; a um ambiente aconchegante, seguro e estimulante; à higiene e à saúde; a uma alimentação sadia; a desenvolver sua curiosidade, imaginação e capacidade de expressão; ao movimento em espaços amplos; a uma especial atenção durante seu período de adaptação à creche (Brasil, 2009b). A busca pela efetivação desses direitos encontra seu alicerce na organização do tempo que procura oferecer, como salientado anteriormente, a segurança necessária para que adultos e crianças transitem pela instituição de modo organizado ou de forma que conheçam antecipadamente os caminhos a trilhar no dia-a-dia da creche.

A segurança necessária para garantir a efetivação daqueles direitos encontra materialidade na rotina, que funciona ritualisticamente, tal como se pode observar nos relatos das professoras acima citados. Essa rotina-ritual busca neutralizar ou minimizar, de forma contínua e previsível, quaisquer perigos que possam ameaçar a organização do trabalho. A rotina-ritual aparece como Lei, mecanismo que, como destaca Ramos (2006), cumpre a tarefa de manter na memória as obrigações e proibições vigentes em uma organização social. Noutros termos, a Lei produz, concomitantemente, lembrança e esquecimento. Lembra o que deve ser executado ou dito, produzindo uma ordem, e, ao mesmo tempo, faz esquecer ou ignorar a condição desejosa, obscura, "impura”, agressiva, erótica, que remonta às forças desconhecidas e indomáveis do inconsciente. (Ramos, 2006). A Lei governa, mas também obstrui, aplaca, circunscreve para que possa haver governo.

Essa Lei que rege o cotidiano da creche colabora para obscurecer questões vinculadas aos impasses entre natureza e cultura, individual e coletivo, contribuindo na determinação de soluções obsessivas: cada um dos momentos que configuram o cotidiano é demarcado por gestos e palavras que se repetem incessantemente e aparecem vinculados à aprendizagem do autocontrole e à busca pela saúde, pela segurança e proteção das crianças, mas também dos adultos. Sobressaem, nas vozes e nas ações das professoras, elementos repetitivamente vinculados ao controle do tempo, ao asseio, à limpeza, à organização, à disciplina que impõem a si mesmas e aos pequenos. 
Nos momentos de chegada, que ocorrem entre sete e oito horas da manhã, pais, avós, vizinhos, irmãos, profissionais que trabalham com transporte escolar, deixam as crianças na entrada da creche ou as encaminham para as salas. Os pequenos dirigem-se às professoras auxiliares, penduram suas mochilas em locais previamente delimitados e escolhem jogos, livrinhos ou outros materiais. As auxiliares orientam o momento atentando para a organização das mochilas, segurança física e uso adequado dos materiais que os pequenos manipulam.

Com a chegada da professora, às oito horas, as crianças são cumprimentadas e convidadas a realizar a higiene antes de se dirigirem ao refeitório para a colação matinal. Neste momento, são orientadas a lavar e secar as mãos e, em seguida, deslocam-se, predominantemente em coluna, para o refeitório. $\mathrm{O}$ almoço acontece a partir das dez e trinta horas, sendo os bebês alimentados em sala. À tarde, após o momento de sono, é oferecido o lanche. O jantar é servido a partir das dezesseis e quinze.

Os primeiros momentos de alimentação aparecem assim registrados em nosso diário de campo:

A professora caminha de mãos dadas com duas crianças. As demais seguem em fila pelo corredor escuro. [...] A professora busca um cacho de bananas e começa a distribuir, circulando em torno da mesa. Repete o trajeto, agora trazendo um prato, para que as crianças depositem as cascas. Pede para as crianças que "sentem direitinho". Duas outras professoras acompanham a turma que agora entra no refeitório. Uma delas descasca bananas e entrega: uma a uma. Seu corpo está curvado sobre a mesa cuja altura é inferior à das demais. Após distribuir as frutas, come também. [...] Uma auxiliar se aproxima, cumprimenta e diz: "Estamos na luta, né?! Hoje acordei cinco para sete, enfiei a roupa e vim. Tenho que estar aqui às sete. Queria lavar os cabelos". Nesse ínterim, outra professora recolhe cascas com uma das mãos e com a outra passa um pano úmido sobre a mesa.

No que se refere aos momentos de alimentação, professoras e auxiliares destacam que: "É servir os alimentos, estimular para eles comerem. Cobrar postura na mesa. É mais organizar mesmo"; "Botamos todos juntos para ir ao refeitório. [...] A mesa que tá vaga eles vão.” E ainda: “É hora de papar. É hora de ir para o refeitório, todos vão. Vai ficar 
sentadinho. Não quer comer, não come, mas fica aqui. A gente não pode deixar sair. Vou cuidar só daquele, aí não dá. Tem regras que não dá para ser quebradas.”

Após o lanche e a higiene, segue-se o momento de atividade orientada, ocasião em que professoras organizam propostas de pintura, desenho, conto, modelagem, entre outras. Essas práticas, geralmente organizadas no espaço da sala, aparecem assim descritas em nosso diário:

São nove horas. Alguns meninos são convidados a "sentarem direito" enquanto a professora amarra os sapatos e o cordão da bermuda de outro. [...] Às 9:15h a professora avisa que irá contar uma história apresentando as ilustrações contidas no livro. Entretanto, diz ela: "Não vou mostrar enquanto estiverem conversando". [...] A história é acompanhada de gestos, vozes enfáticas, expressões e ritmos diferentes, atraindo a atenção das crianças que solicitam "mais uma". Mas o momento seguinte já está preparado: todos devem sentar "sem arrastar as cadeirinhas" e desenhar um dos personagens. Durante a atividade, sempre que se eleva o tom de voz das crianças a professora intervém: "Deu agora!" Circulando entre as mesas, enquanto a professora registra o título da história nos blocos chama a atenção de um menino que "hoje está muito teimoso", e também emite juízos a respeito dos desenhos: "Que bonito!" "O que tu fez ?" Às 9:47h os blocos são recolhidos; as crianças são auxiliadas a retirar e guardar os casacos e encaminhadas ao parque. [...] O garoto teimoso ficará "de castigo", próximo à professora que guarda os lápis de cor, dispõe as cadeirinhas sobre as mesas e exclama: "Meu Deus, hoje tem que colocar os lençóis".[...] Ocorre uma briga no interior da casinha, em função da disputa pelo espaço, e duas professoras intervêm. A auxiliar comenta: "A casinha me deixa mais velha". Outra sugere que "deveria ser trancada à chave".

Com relação aos momentos de parque, uma professora destaca:

Eu acho que são poucos brinquedos e estragados. Deveria ter outras opções. Eu sinto que o parque fica muito violento. Aquela coisa que eles correm até lá embaixo. Aí de uma pedra eles fazem um brinquedo. [...] Tu perde aquele controle. [...] Nós temos uma casinha, mas não tem brinquedo. Qual é o atrativo? O atrativo é trancar a porta e eles ficam lá dentro. Ou eles se beijam, ou eles tiram a roupa, ou eles machucam alguém. O esconderijo deles é na casinha. Se tivesse brinquedo seria utilizada de outra maneira.

Do parque, as crianças são conduzidas ao banheiro e, em seguida, ao refeitório para o almoço: 
A professora busca pratos de sopa e uma bacia branca com arroz. Novamente repete o trajeto, trazendo farinha de mandioca. Manda que as crianças "sentem direito". Serve arroz em dois dos pratos. Em seguida, uma concha de picadinho. Larga os pratos, os pega novamente e enquanto entrega a duas crianças, diz: "Senta, senta, senta. Quem não comer não vai assistir ao vídeo". Serve mais dois pratos. E segue. Alguns comem com as mãos. Termina de servir as dezenove crianças e passa a distribuir os talheres. Então se serve e rapidamente leva comida à boca. Uma criança tenta devolver a comida e, antes que conclua uma palavra, é interrompida: "Não quero ouvir o que tu vai dizer. Come". Começa a recolher as bacias. Busca um pano, limpa a mesa, sempre repetindo: "Pode terminar de comer". "Pode comer". "Tu pediu, agora come".

A professora convida as crianças que "estiverem prontas" a retornarem à sala para "escovar os dentes". Segue em fila com o grupo e solicita que sentem recostados à parede enquanto os demais escovam os dentes: três a três, as crianças são encaminhadas ao banheiro depois que a pasta dental é colocada sobre as escovas. Durante a escovação ouvese: "Deu". "Molha a escova". "Anda". "Deu". "Vai".

Após a higiene e a retirada dos calçados, as crianças se dirigem aos colchonetes, onde se acomodam rapidamente e em silêncio ou, como ocorre na maior parte das vezes, rolam de um lado ao outro, saltam, viram cambalhotas, "lutam", brigam, conversam, até que vozes adultas intervenham. Então se escuta: "Deu”. "Aqui no teu colchão". "Desgruda. Sossega." "Deita lá." "Vira." "Chega para cá." "Vou te levar para o berçário." "Para de conversa." "Vira a cabeça." "Sem conversa." "Psiu." "Se você dormir tarde eu vou te acordar bem cedo." "Mão de anjinho e olhinho fechado que o sono vem." No caso das crianças denominadas "danadas", 4 os bramidos, lançados de tempos em tempos, são acompanhados por massagens, carícias doadas pelas auxiliares que, persistentemente, permanecem ao lado desses pequenos, avisando: "Não adianta, que não vou te largar até dormir."

\footnotetext{
${ }^{4}$ Desta vez se coloca um vocabulário que remete a uma das tradições de compreensão da infância, aquela que oscila entre a consideração de que seriam as crianças ora "anjos" a serem admirados, ora "demônios" a serem corrigidos - em um plano mais geral, o trabalho de Gagnebin (1997), oferece uma interessante reflexão sobre esse tema. Condenadas à "danação" são as crianças que se equiparam, em uma tradição religiosa, aos "demônios".
} 
Após o despertar se inicia um novo ciclo: higiene-alimentação-higiene-parquehigiene-jantar-higiene e saída, quando, após a despedida da professora, às dezessete horas, a auxiliar permanece com as crianças, até às dezenove, no parque ou na sala, aguardando a chegada dos pais. Sua tarefa é também organizar o espaço e os materiais, orientando as crianças, intervindo diante de conflitos e assegurando a segurança dos pequenos, tal como acontece nos momentos de chegada.

Da creche, algumas profissionais se deslocam para distintos lugares. Há professoras cursando Magistério, em formação superior ou frequentando cursos de especialização na área da Educação. Outras se dirigem até o médico, ao curso de cabeleireiros, entre tantas atividades, ou cuidam de seus filhos/as e netos/as. Limpam a casa, passeiam com familiares, lavam ou passam roupa, planejam atividades, ocupam-se de passatempos, como a assistir televisão, pois, como salienta a professora: "Adoro ver televisão. Adoro sentar, ver televisão, ver filme, novela. Adoro! Esqueço do mundo porque a gente trabalha o dia inteiro." Recoloca-se a dinâmica dos esquemas da indústria cultural, em que a recuperação para o trabalho surge como fim último das práticas do "tempo livre". Livrar-se de tudo aquilo que lembre o trabalho, mesmo que se coloque em seu lugar o caráter disciplinador da diversão (Horkheimer; Adorno, 1985) é o que parece ser procurado pela professora depois das horas de desgaste na creche.

Crianças e adultos circulam por diferentes espaços, para depois adormecer, talvez sonhar e, então, despertar para uma nova chegada à creche. $\mathrm{Na}$ alvorada de cada novo dia observamos as professoras orientando os momentos de higiene, lavando os rostos das crianças, penteando-lhes e enfeitando os cabelos, solicitando que retirem ou coloquem casacos, limpando narizes, trocando fraldas, banhando, perfumando, levando ao sol para que "não mofem" e ao parque para que "extravasem as energias". Nos momentos de alimentação, distribuem e recolhem pratos e talheres, recolhem restos, passam panos sobre as mesas, oferecem alimentos salientando as benfeitorias de uma prática comensal saudável. Em sala, além de distribuir materiais e orientar atividades, apontam lápis, colam bilhetes nas agendas das crianças, organizam o espaço, empilham cadeiras, abrem e fecham janelas, dispõem e recolhem colchonetes para o sono, trocam lençóis. Cobrem, 
massageiam, acariciam e gritam com os pequenos para que adormeçam. No parque, orientam as crianças frente a possíveis atitudes e gestos vistos como perigosos, determinam a direção no uso dos brinquedos, controlam quaisquer movimentos que possam oferecer riscos. Também no parque observa-se, com frequência, as professoras reunidas em círculo, num movimento de distanciamento do olhar, como quem busca um momento de afastamento dos pequenos. Quando novamente se dirigem às crianças, a atenção recai sobre aspectos vinculados à assistência, à proteção, à segurança, ao uso adequado dos materiais e espaços, a regras que, como destacado, "não podem ser quebradas". Para tal, fazem uso de recursivas ameaças, castigos, elogios, reprimendas, premiações que reforçam a exigência da eliminação de "falhas" e "desvios" das crianças. Tudo o que possa lembrar uma natureza a ser dominada deve ser superado e corrigido.

Observamos um investimento sobre o corpo e seus descontroles, sobre o quê se exige renunciar em nome da civilidade. Busca-se eliminar cheiros, ruídos, atitudes desgovernadas, enfim, tudo aquilo que aparece como estranho e que não deve, como dito anteriormente, ser lembrado. Como sugere Ramos (2006), deve-se retirar da consciência os impulsos que ganham forma no desejo pelo proibido e, ao mesmo tempo, fazer lembrar das proibições, criando uma memória que seja suficientemente forte para garantir a manutenção das leis morais.

O estranho representa tudo aquilo que causa aflição, incerteza, mas também o quê as boas maneiras obrigam a esconder. Trata-se do que amedronta, de elementos que, embora possam ser familiares, alienam-se no processo de repressão: resíduos ou traços do que é reprimido no processo civilizador, mas que retornam na forma da repetição. Segundo Ramos (2006:14), “quando o sujeito não pode ou não consegue lembrar de algo recalcado que insiste em retornar à consciência, ele expressa o recalcado na forma de ação", tal como se observa nos rituais presentes na creche e que compreendem a minuciosa e repetitiva execução de uma série de atos para evitar perigos, machucados, desordem. Essa busca pela ordem e pelo asseio engendra, como destaca Lastória (2004:140), um conjunto de "atitudes de domesticação dos impulsos sexuais enquanto imperativos da civilização ocidental." Coloca-se como uma luta, uma guerra para dissipar tudo que aparece associado à confusão, 
à agitação ou que escapa ao controle. Quando a professora, ao chegar à creche, anuncia que vai "vestir minha roupa de guerra" para começar a trabalhar ou ao dizer "estamos na luta, não é?!", ou, ainda, quando termina o momento do intervalo verbalizando que retornará ao trabalho com a expressão "vamos lá, o repeteco", expressa, de forma realista, os esquemas em que baliza sua atuação: uma batalha diária que é reconhecida como repetição incessante do mesmo, operação defensiva de sobrevivência no mundo administrado.

Essa operação defensiva toma forma de compromisso que, segundo Adorno (2000:124),

facilmente converte-se em passaporte moral - são assumidos com o objetivo de identificar-se como cidadão confiável - ou então produzem rancores raivosos psicologicamente contrários a sua destinação original. Eles significam uma heteronomia, um tornar-se dependente de mandamentos, de normas não são assumidas pela razão própria do indivíduo.

Adorno (2000) lembra que aqueles rancores engendram uma inclinação arcaica à violência, como tendência regressiva que pode ser expressa por meio de uma relação patogênica com o corpo: "em cada situação que a consciência é mutilada, isso se reflete sobre o corpo e a esfera corporal de uma forma não livre, propícia à violência." (Adorno, 2000:127). Violência que se expressa na linguagem, nos gestos e também na ideia de autoridade convertida em severidade, culminando no elogio à educação baseada na força e orientada para a disciplina e a dureza: indiferença à dor em geral, mas também incapacidade de realizar experiências, substituindo-as por um realismo exagerado, pela ausência de fantasia e pelo apego compulsivo à ordem (Adorno, 2000).

Adorno (2000) sugere que a escola apresenta a tendência de "se estabelecer como esfera própria da vida e dotada de legislação própria" (Adorno, 2000:114), ratificando a ideia de que a realidade não pode ser diferente do que é. Restaria repeti-la por meio da rotina-ritual, produzindo um cotidiano que conserva a estabilidade, a previsibilidade, a segurança e a unidade no interior da instituição, bem como a eficiência das ações. No dia-adia da creche, tudo se converte em tarefa, num seguir as regras do jogo, fazer e dizer o que é adequado segundo a norma reconhecida para legitimar a ordem: "a harmonia do inconciliável favorece a preservação da má totalidade” (Adorno, 1993:160), ou seja, uma 
ordem que procura não deixar brechas para sua autocrítica, na medida em que tudo reduz a um denominador comum submetido a uma autoridade abstrata.

\section{Dos intervalos na rotina ou da rotina nos intervalos}

Ao longo do itinerário que compreende o dia-a-dia da creche, as professoras dispõem de uma hora para almoçar e de intervalos para lanche, de manhã e à tarde. Esses intervalos são nomeados por elas com a expressão "Os quinze”, em função do tempo destinado. Com frequência escuta-se alguma professora anunciando: "Vou fazer os quinze." Esses momentos aparecem assim descritos em nosso diário de campo:

Às 15:05h a professora entra rapidamente, senta no banco mais próximo à porta do refeitório que ainda não foi limpo. Abre uma garrafa plástica de suco de laranja e, de um pacote de papel pardo, retira um "pão-doce". Ao lado, coloca algum dinheiro. Às 15:08h, bebe, num só gole, o resto do suco enquanto levanta e, já em pé, amassa o papel em que o pão estivera envolvido. Leva ao lixo e sai. [...] Às 15:21h, com um pacote de papel pardo, idêntico ao anterior, outra professora entra no refeitório. Perguntamos a respeito do embrulho e comenta: "Algumas compram [o lanche] aí na padaria, aí na frente". Serve refrigerante em um copo plástico e começa a lanchar: "Pão doce de coco". Conta que, geralmente, tomam café feito pelas merendeiras, mas pago por elas. Como faz calor trouxe refrigerante, que já havia comprado no dia anterior. Oferece a bebida e às 15:24h, quando outra professora se aproxima, já encerrou a refeição.

Com relação ao período de almoço, uma professora explica:

Mas o momento de horário do almoço acaba ficando meio... Primeiro, a gente não tem um lugar para se recolher, se eu quiser ficar sozinha num lugar é meio complicado. Eu fico na sala. Normalmente eu descanso com as crianças. Quando eu consigo. O momento de intervalo é o lanche, quinze minutos de intervalo, e no horário do almoço.

Esses momentos são traduzidos pelas professoras como o período em que "a gente conversa, faz fofoca quando vê uma professora gritando, fala do marido, de roupa. Vem vendedora e a gente compra". Ou ainda: "Ela [uma colega] vai, faz 'os quinze', depois eu faço. O café cada funcionário traz. Cada um vai na padaria, traz. Esse momento, para mim, nem sempre é legal. Muito difícil de rir, brincar. É um momento de trocar problemas, dificuldades." 
Nos intervalos, as professoras comem, apressadas, lanches geralmente adquiridos na padaria em frente à creche e comprados antes de ingressar na instituição para uma nova jornada de trabalho ou no início da pausa. Além disso, também cultivam o hábito de alimentar-se enquanto se deslocam para o trabalho, como no ônibus, por exemplo e em seus lares preferem comer "lanches rápidos". O tempo livre" das professoras também corre ao ritmo do trabalho: maquinal, efêmero. Nele ganha espaço a informação abreviada, como se pôde observar nos inúmeros assuntos discutidos por elas nas pausas. É a comunicação "que cuida da assimilação dos homens, isolando-os” (Horkheimer; Adorno, 1985:207).

\section{Das paradas pedagógicas na rotina ou da rotina nas paradas pedagógicas}

As paradas pedagógicas são encontros mensais, realizados na própria creche, em que as profissionais se reúnem para estudos e discussões administrativo-pedagógicas durante um período equivalente a oito horas/aula.

A cena abaixo ilustra um momento de parada registrado em diário:

São 13:38h. A pauta inicial trata da organização "da semana da criança". Fala-se sobre a organização das salas e sugere-se que sejam decoradas a partir dos temas "Sítio" e "A Casa da Bruxa". Uma professora sugere que levem as crianças "para a rua" e que as professoras apresentem uma peça de teatro. A diretora sugere uma oficina e que as crianças recebam presentes confeccionados pelas professoras. Uma auxiliar sugere que se faça uma "pescaria" e que cada criança receba um "brinde". Fica pré-estabelecido que, no decorrer da semana, haverá uma peça de teatro, oficinas e uma festa. [...] Em seguida a supervisora destaca que "falta um dia" e uma professora sugere "passeio no trem da Alegria". E conclui: "Eu gosto tanto de passear no trem". [...] Ainda são sugeridos: karaokê, desfile de fantasias confeccionadas em um turno e apresentadas em passarelas no turno seguinte. Após anunciar que a prefeitura não dispõe de ônibus, que se poderia procurar "políticos, pois é ano de eleição", que poderiam solicitar aluguel de cama-elástica e piscina de bolinha, a supervisora procura encerrar a questão registrando no quadro as datas, as atividades programadas e as professoras responsáveis. A diretora sugere que, nesse dia, o momento do sono seja reestruturado e logo se ouve: "Aí não vai dar". "Sujou". "Tem que ter horário por causa do lanche, da rotina."

\footnotetext{
${ }^{5}$ No tempo livre "se prolonga a não liberdade tão desconhecida da maioria das pessoas não livres como sua não liberdade em si mesma. [...] Segundo a moral do trabalho vigente, o tempo em que se está livre do trabalho tem por função restaurar a força de trabalho, o tempo livre do trabalho, funcionando como seu apêndice." (Adorno, 1995:71-73).
} 
As paradas pedagógicas, ao contrário da ideia de interrupção no continuum do tempo (Benjamin, 1993:230-231), aparecem como uma marcha para frente, um tempo repleto de fatos, datas, normatizações, ou como possibilidade de restabelecer cronogramas já consagrados. Programar uma festividade, como se pode observar na cena acima, implica em “doing things, going places" (Adorno, 1993:122), conformando uma pseudoatividade que é “um resseguro, é a expressão da disposição para auto-renúncia, único meio pelo qual ainda se presume garantir a autoconservação." (Adorno, 1993:122). As professoras planejam a organização da "semana da criança" como doing things, going places (passeio no trem da alegria, distribuição de brindes, desfile de fantasias, karaokê etc.), contanto que não interfiram na rotina, como se observa na passagem em que uma profissional sugere a reestruturação do momento de sono e, de imediato, escuta: “Aí não vai dar”, "Sujou”, “Tem que ter horário por causa do lanche, da rotina."

Nos diferentes momentos da rotina, nos intervalos e paradas pedagógicas, observase uma intensa preocupação com a alimentação. Seguindo uma sugestão de Lastória (2004), observamos a supremacia das práticas comensais como uma possibilidade de gozo em meio a tanta renúncia, alcançando um tipo de satisfação somática perante os desprazeres.

\section{Notas Finais}

Entrar na creche, "vestir a roupa de guerra", varrer, organizar materiais, colchonetes, cadeiras, escovas dentais, mochilas, pratos, talheres e toalhas, distribuir brinquedos, alimentar, trocar, banhar, pentear, fazer adormecer, cobrir, organizar atividades, conduzir e circular de um espaço ao outro, realizar "os quinze", almoçar, participar de paradas pedagógicas, lanchar, controlar, assegurar a limpeza, a ordem, a higiene das crianças e dos espaços e evitar o aparecimento de feridas expostas (pois, como anuncia uma professora, ao final do dia na creche, as crianças devem "estar inteiras") e, finalmente voltar para casa para "assistir televisão", para "esquecer o mundo" porque "se trabalha o dia inteiro", tudo isso compõe o cotidiano das professoras.

A prática pedagógica parece percorrer tempos e espaços que se pretendem livres de conflitos e tensões, mantendo uma espécie de equilíbrio precário para conservar a estabilidade e a previsibilidade, a segurança e a unidade no interior da instituição, bem 
como a eficiência das ações. Essa constância, que encontra no rito o seu modus operandi, estabelece marcas que instituem padrões, procedimentos, técnicas, que ordenam os corpos das crianças e dos adultos, os sentidos, os comportamentos, as ações e a comunicação pedagógica. Sua legitimidade reside na produção da ordem racional que se traduz na eliminação de desvios, no abandono da expressão mimética e na abdicação do pensamento em favor de uma prática vinculada à aplicação de técnicas e procedimentos sistemáticos materializados em hábitos e rotinas. Outrossim, aquele equilíbrio é fortalecido por tabus que pairam sobre a profissão de ensinar e que retroagem sobre a realidade, convertendo-se em forças reais, tal como a imagem do professor como alguém excluído da esfera erótica, ou neutralizado do ponto de vista erótico, e que, por habitar um ambiente infantil, não é considerado inteiramente adulto (Adorno, 2000). Os tabus, segundo Freud (2006), aproximam-se das proibições obsessivas, sobretudo em relação ao tocar (fobia de contato), ao medo de uma ação proibida para cuja realização existe forte inclinação inconsciente, uma vez que eles têm a qualidade de "provocar desejos proibidos" (Freud, 2006:49). Talvez possamos pensar na relação entre a fala das professoras, anteriormente referida, a respeito da casinha presente no parque, onde, segundo elas, as crianças "ou tiram a roupa ou se beijam", uma vez que o tabu tem o poder de fazer alguém presentificar seus desejos proibidos e de induzir a transgressão da proibição em obediência ao desejo. Daí sua intenção manifesta de "trancar a casinha à chave".

Horkheimer e Adorno (1985) salientam o pavor diante do retorno ao primitivo, ${ }^{6}$ àquilo que renunciamos, aos impulsos que, de forma obscurecida, expressam a natureza não racional. Para eles, “o perigo que ameaça a prática dominante e suas alternativas inevitáveis não é a natureza - a natureza, muito ao contrário, coincide com ela -, mas sim o fato de recordar da natureza." (Horkheimer e Adorno, 1985:235-237).

O medo extremo do retorno ao primitivo talvez encontre expressão nas ameaças, nos castigos, nos gritos das professoras, como também nos comportamentos repetitivos e

\footnotetext{
${ }^{6}$ Horkheimer e Adorno (1985:230-231) escrevem: “A transformação das pessoas em animais como castigo é um tema constante nos contos infantis de todas as nações. Estar encantado no corpo de um animal equivale a uma condenação. Para as crianças em diferentes povos a idéia de semelhantes metamorfoses é imediatamente compreendida e familiar [...]".
} 
incessantes que asseguram o asseio e a ordem. Mas, também, talvez, se expresse no gesto de se reunir em círculo no parque, ocasião em que dão as costas às crianças numa tentativa de afastamento desse outro, da infância e do corpo que insistem em lembrar tudo aquilo que se coloca como proibido, incompleto, inacabado, ou ainda, movidas pelo esforço em não se deixar misturar ao universo lúdico, indeterminado, confuso, não soberano: que faz recordar não apenas nossa natureza não racional, mas revela também que tudo o que está aí pode ser outra coisa (Gagnebin, 1997). Esse medo permanece sempre à espreita, uma vez que a presença das crianças e seus desajustes são permanentes. Da mesma forma também é constante a luta cotidiana das professoras em apagar aquele poder misterioso, estranho (Uhnheimlich) que caracteriza os pequenos como estrangeiros, diferentes do adulto.

A palavra tabu, para os antigos romanos, equivale a sacer, sagrado. A fundamentação da função da Educação Infantil nos direitos das crianças talvez reafirme a condição infantil como sacer: uma vida que não pode ser tocada ou dada em sacrifício. Mas essa vida pode muito bem ser, se seguimos as sugestões de Agamben (2004), matável, no sentido muito preciso do esquecimento ou da tentativa de aniquilamento do desejo, como também do apagamento da capacidade mimética que se caracteriza como uma forma de aprendizado, de produção do saber, de (re)conhecimento e aproximação não dominadora junto aos objetos.

Talvez essas "personagens", as crianças, invertam a Lei na medida em que não retêm, de imediato, as obrigações na memória e se permitam lembrar do desejo proibido. As professoras, por sua vez, lutam para que a Lei seja lembrada e perdure. As pistas deixadas por Adorno (2000:99) ganham, nesse contexto, insuspeita importância: os professores "não devem sufocar suas reações afetivas, para acabar revelando-as em forma racionalizada, mas deveriam conceder essas reações afetivas a si próprios e aos outros.”

\section{Referências}

Adorno, T. (1993) Minima Moralia: reflexões sobre a vida danificada. 2. ed. São Paulo: Ática.

Adorno, T. (1995) Palavras e sinais: modelos críticos 2. Petrópolis: Vozes. 
Adorno, T. (2000) Educação e emancipação. 2. ed. São Paulo: Paz e Terra.

Agamben, G. (2004) Homo Sacer: o poder soberano e vida nua. Belo Horizonte: UFMG.

Benjamin, W. (1993) Obras escolhidas I. 4. ed. São Paulo: Brasiliense.

BRASIL. (2009a) Ministério da Educação. Secretaria de Educação Básica. Indicadores da Qualidade na Educação Infantil. Brasília: MEC/SEB.

BRASIL. (2009b) Ministério da Educação. Secretaria de Educação Básica. Critérios para um Atendimento em Creches que Respeite os Direitos Fundamentais das Crianças. Ministério da Educação. Brasília: MEC/SEB.

BRASIL. (2006) Ministério da Educação. Secretaria de Educação Básica. Política Nacional de Educação Infantil: pelo direito das crianças de zero a seis anos à educação. Brasília: MEC/SEB.

BRASIL. (2005) Ministério da Educação. Proinfantil: Programa de Formação Inicial para Professores em Exercício na Educação Infantil: diretrizes gerais. Brasília: MEC.

BRASIL. (1998) Ministério da Educação e do Desporto. Secretaria de Educação Fundamental. Referencial curricular nacional para a educação infantil. Brasília: $\mathrm{MEC} / \mathrm{SEF}$.

Freud, S. (2006) uma neurose infantil e outros trabalhos (1917-1918). Rio de Janeiro: Imago.

Freud, S. (2006) Totem e tabu e outros trabalhos (1913-1914). Rio de Janeiro: Imago.

Gagnebin, J. M. (1997) Sete aulas sobre linguagem, memória e história. Rio de Janeiro: Imago.

Horkheimer, M. y Adorno, T. (1985) W. Dialética do esclarecimento: fragmentos filosóficos. Rio de Janeiro: Zahar.

LASTÓRIA, L. A. C. N. (2004) Os topos psicológicos no interior da Teoria Crítica da Sociedade. In: ZUIN, A. A. S.; PUCCI, B.; RAMOS-DE-OLIVEIRA, N. (Orgs.). Ensaios frankfurtianos. São Paulo: Cortez, 2004. p. 137-150. 
Ramos, C. O (2006) Ressentimento do guerreiro: reflexões sobre o corpo e a educação a partir do pensamento de Theodor Adorno e da Psicanálise. Interações, 11, 21, 9-28.

Richter, A C. y Vaz, A. F. (2005) Corpos, saberes e infância: um inventário para estudos sobre a educação do corpo em ambientes educacionais de 0 a 6 anos. Revista Brasileira de Ciências do Esporte, 26, 3, 79-93.

VAZ, A. F. (2002) Aspectos, contradições e mal-entendidos da educação do corpo e a infância. Motrivivência, , 13, 19, 7-11. 